\title{
Article \\ ZnO Nanoparticles Induce Dyslipidemia and Atherosclerotic Lesions Leading to Changes in Vascular Contractility and Cannabinoid Receptors Expression as Well as Increased Blood Pressure
}

\author{
Adriana Ceballos-Gutiérrez ${ }^{1}$, Alejandrina Rodríguez-Hernández ${ }^{1}$, María del Rosario Álvarez-Valadez ${ }^{2}$, \\ Saraí Limón-Miranda ${ }^{3}$, Felipa Andrade ${ }^{4}$, Alejandro Figueroa-Gutiérrez ${ }^{1}$, Irene Díaz-Reval ${ }^{2}$, \\ Alejandro Apolinar-Iribe ${ }^{5}$, Luis Castro-Sánchez ${ }^{6}{ }^{\mathbb{D}}$, Javier Alamilla ${ }^{6}$, Enrique Sánchez-Pastor ${ }^{2, *}$ (]) \\ and Adolfo Virgen-Ortiz ${ }^{2, *}$
}

check for updates

Citation: Ceballos-Gutiérrez, A.; Rodríguez-Hernández, A.;

Álvarez-Valadez, M.d.R.;

Limón-Miranda, S.; Andrade, F.;

Figueroa-Gutiérrez, A.; Díaz-Reval, I.; Apolinar-Iribe, A.; Castro-Sánchez, L.; Alamilla, J.; et al. ZnO Nanoparticles Induce Dyslipidemia and Atherosclerotic Lesions Leading to Changes in Vascular Contractility and Cannabinoid Receptors Expression as Well as Increased Blood Pressure. Nanomaterials 2021, 11, 2319. https:// doi.org/10.3390/nano11092319

Academic Editors: Luisa Fiandra and Steven Wise

Received: 20 July 2021

Accepted: 2 September 2021

Published: 7 September 2021

Publisher's Note: MDPI stays neutral with regard to jurisdictional claims in published maps and institutional affiliations.
1 Facultad de Medicina, Universidad de Colima, Colima 28040, Mexico; aceballos12@ucol.mx (A.C.-G.); arodrig@ucol.mx (A.R.-H.); afigueroa3@ucol.mx (A.F.-G.)

2 Centro Universitario de Investigaciones Biomédicas, Universidad de Colima, Colima 28045, Mexico; Malvarez52@ucol.mx (M.d.R.Á.-V.); idiazre@ucol.mx (I.D.-R.)

3 Departamento de Ciencias Químico Biológicas y Agropecuarias, Unidad Regional Sur, Universidad de Sonora, Navojoa 85880, Mexico; Sarai.limon@unison.mx

4 Institito Tecnológico de Colima, Colima 28076, Mexico; Felipa.andrade@colima.tecnm.mx

5 Departamento de Física, Unidad Centro, Universidad de Sonora, Hermosillo 83000, Mexico; apolinar@ciencias.uson.mx

6 Centro Universitario de Investigaciones Biomédicas, CONACYT-Universidad de Colima, Universidad de Colima, Colima 28045, Mexico; Luis_castro@ucol.mx (L.C.-S.); javier_alamilla@ucol.mx (J.A.)

* Correspondence: espastor@ucol.mx (E.S.-P.); avirgen@ucol.mx (A.V.-O.); Tel.: +52-312-3161129 (E.S.-P.)

\begin{abstract}
ZnO}$ nanoparticles (ZnONPs) have been shown to have therapeutic potential in some diseases such as diabetes and cancer. However, concentration-dependent adverse effects have also been reported. Studies which evaluate the effects of ZnONPs on the cardiovascular system are scarce. This study aimed to evaluate the cardiovascular effects of a low dose of ZnONPs administered chronically in healthy rats. Changes in dyslipidemia biomarkers, blood pressure, aortic wall structure, vascular contractility, and expression of cannabinoid receptors in the aorta wall were evaluated. Healthy rats were divided into two groups: control or treated (one, two, and three months). The treated rats received an oral dose of $10 \mathrm{mg} / \mathrm{kg} /$ day. The results showed that treatment with ZnONPs induced dyslipidemia from the first month, increasing atherosclerosis risk, which was confirmed by presence of atherosclerotic alterations revealed by aorta histological analysis. In in vitro assays, $\mathrm{ZnONPs}$ modified the aorta contractile activity in response to the activation of cannabinoid receptors $\left(\mathrm{CB}_{1}\right.$ and $\left.\mathrm{CB}_{2}\right)$. The expression of $\mathrm{CB}_{1}$ and $\mathrm{CB}_{2}$ was modified as well. Moreover, $\mathrm{ZnONPs}$ elicited an increase in blood pressure. In conclusion, long-time oral administration of ZnONPs induce dyslipidemia and atherosclerosis eliciting alterations in aorta contractility, $\mathrm{CB}_{1}$ and $\mathrm{CB}_{2}$ receptors expression, and an increase in blood pressure in healthy rats.
\end{abstract}

Keywords: $\mathrm{ZnO}$ nanoparticles; dyslipidemia; cardiovascular; atherosclerosis; vascular contractility; blood pressure; cannabinoid receptor; $\mathrm{CB}_{1}$ receptor; $\mathrm{CB}_{2}$ receptor

\section{Introduction}

Zinc oxide nanoparticles (ZnONPs) are being studied widely due to their multiple applications. Previous works on biological systems show that ZnONPs have antibacterial, antifungal, antiviral, anticancer, and antidiabetic activity. In the field of engineering, it has been reported that ZnONPs are useful in solar cells, gas sensors, chemical sensors, biosensors, and photodetectors [1]. The potential of therapeutic application of these nanoparticles is promising for the treatment of chronic diseases such as diabetes mellitus [2-7]. Thus, 
more research is needed to evaluate in detail their biological and toxicological effects in different tissues after long periods of administration. The effect of ZnONPs depends on their physicochemical properties, exposure time, dose or concentration, $\mathrm{pH}$, and biocompatibility. ZnONPs have been reported to release zinc ions capable of inducing oxidative stress and cell damage, generating a cytotoxic and genotoxic effect. Although there are studies that have evaluated the effects of ZnONPs on some organs or systems, the current knowledge is limited. Toxicity studies mainly at high doses of ZnONPs have shown accumulation of zinc in the liver, kidney, lung, heart, and spleen, inducing injury and in some cases death [8]. Other studies also showed this type of effect was induced by ZnONPs, but dependent on the route of administration [9]. Hematological alterations, stomach, pancreas, and retina injuries have also been reported [10] and, more recently, alterations in the nervous system [11,12].

In this context, recent studies have evaluated the effects of ZnONPs on the cardiovascular system reporting interesting observations $[13,14]$. First, in an in vitro test with human coronary artery endothelial cells, they observed inflammation and an increase in cell adhesion molecules expression in a concentration-dependent manner. They later observed in an in vivo trial that ZnONPs induce dyslipidemia, systemic inflammation, and an increase in the thickness of the aortic wall, suggesting that ZnONPs can produce atherosclerotic alterations at very low doses administered intratracheally [13]. In contrast, another study carried out in healthy rats showed that low doses of ZnONPs administered intragastrically did not affect the metabolic biomarkers that evaluate atherogenic risk. However, at doses of $10 \mathrm{mg} / \mathrm{kg}$, systemic inflammation was observed [14].

The lack of knowledge of the ZnONPs' effects on the cardiovascular system, as well as the discrepancies in the risk of generating atherosclerosis, made us propose a study to evaluate the effects of a low dose of ZnONPs administered chronically on blood pressure, structure of the aortic wall, dyslipidemia biomarkers, and vascular contractility. On the other hand, pathophysiological studies carried out to better understand the mechanisms involved in atherosclerosis suggest an important role of the endocannabinoid system in the progression of this disease [15-18]. Thus, it was also in our interest to evaluate in this study whether the atherosclerotic alterations induced by $\mathrm{ZnONPs}$ are associated with changes in the expression of $\mathrm{CB}_{1}$ and $\mathrm{CB}_{2}$ cannabinoid receptors in the aorta wall.

\section{Materials and Methods}

\subsection{Animals}

Male rats of the Wistar strain with an average weight of $310 \pm 10 \mathrm{~g}$ were used for the study. All the animals were kept in a room with controlled temperature conditions $\left(24^{\circ} \mathrm{C}\right)$ and 12:12 h of light-dark cycles. During all experimental protocols they had free access to water and food. All the procedures used were approved by the bioethics committee of the University Center for Biomedical Research of the University of Colima (Project code 2020-1; approval date: 12 February 2020).

\subsection{Experimental Design}

Sixty rats were randomly divided into two experimental groups: control $(n=30)$ and treated with $\mathrm{ZnONPs}(10 \mathrm{mg} / \mathrm{kg}, n=30)$, then each group was subdivided into three groups ( $n=10$ per group) corresponding to one, two, and three months of treatment.

\section{3. $\mathrm{ZnONPs}$ Preparation}

ZnONPs dispersion was purchased from Sigma-Aldrich (catalog number 721077, St. Louis, MO, USA). For the treatment, a fresh dispersion was prepared at a concentration of $5 \mathrm{mg} / \mathrm{mL}$ diluted in $0.9 \%$ sodium chloride solution. In order to have a homogeneous dispersion, the mixture was sonicated in an ultrasonic bath with pulse cycles of $30 \mathrm{~s}$ and $30 \mathrm{~s}$ of rest, and a pulse amplitude of $50 \%$. Freshly dispersed the ZnONPs were administered intragastrically with a daily dose of $10 \mathrm{mg} / \mathrm{kg}$ for one, two, and three months, corresponding to each experimental group. The ZnONPs used in this study have a spherical 
shape, with an average size of $17 \mathrm{~nm}$. These data were previously reported by our research group [19].

\subsection{Measurement of the Blood Pressure in Rats}

Before measuring the blood pressure, for a week the rats were adapted to the restrain tube and acclimatized to the experimentation room. On the day of the experiment, the measurement was carried out as follows: the rat was place into the restraining tube and holders inside tube were adjusted to prevent movement of the animal. Subsequently, a volume pressure recording sensor coupled occlusion cuff was placed on the rat tail base, and measurements were made using a non-invasive Mouse and Rat Blood Pressure System (IITC Life Science Inc, Woodland Hills, CA, USA). Five recordings were made with a 1-min rest between each recording, and the average of the blood pressure was calculated for each rat. This equipment used to measure blood pressure has a high reliability photoelectric sensor to detect pulsation at a room temperature of $32{ }^{\circ} \mathrm{C}$ or less, avoiding stress to the rat and alterations in blood flow due to excessive heat. The rat tail temperature was recorded during the blood pressure measurement $\left(30 \pm 1.5^{\circ} \mathrm{C}\right)$.

\subsection{Biochemical Determinations}

Blood samples were obtained by an intracardiac puncture at 30,60, and 90 days from each experimental group, then the serum was separated by centrifugation at $3000 \mathrm{rpm}$ for five min. The serum was aliquoted and stored at $-80{ }^{\circ} \mathrm{C}$ until later analysis. Following the protocols recommended by the manufacturer (SPINREACT, Girona, Spain), total cholesterol (TC), HDL-cholesterol (HDL-C), LDL-cholesterol (LDL-C), triglycerides (TG), as well as gamma-glutamyl transferase (GGT), alkaline phosphatase (ALP), aspartate aminotransferase (AST), alanine aminotransferase (ALT), and lactate dehydrogenase (LDH) enzymes were determined in the samples.

The atherogenic index was calculated from the equation: Log10 (TG/HDL-C).

\subsection{Histological Analysis}

In each experimental group, the descending aorta was removed, placed in a Sylgardcoated Petri dish filled with oxygenated Krebs-Henseleit (SKH) solution, to remove surrounding adipose and connective tissue. A fragment of the aorta was fixed in $10 \%$ buffered formalin, embedded in paraffin, cut ( $5 \mu \mathrm{m}$ sections), and stained with the hematoxylineosin technique for histological analysis. Another fragment of the aorta was used for the study of vascular contractility, and the immunohistochemical analysis.

\section{7. $C B_{1}$ and $C B_{2}$ Receptors Expression in Aorta Rings by Immunofluorescence}

$\mathrm{CB}_{1}$ and $\mathrm{CB}_{2}$ receptor expression in the aorta wall was studied immunohistochemically followed by confocal microscopy. Cross sections $(2 \mathrm{~mm})$ of the aorta were fixed in $4 \%$ paraformaldehyde, embedded in paraffin, cut, place on a slide, deparaffinized, and rehydrated. Next, aorta sections were blocked (Animal-free blocker and diluent, Vector laboratories Inc., Burlingame, CA, USA) and incubated with rabbit polyclonal Anti-CB ${ }_{1}$ (1:100, Alomone, Labs, Jerusalem, Israel) or rabbit polyclonal Anti- $\mathrm{CB}_{2}$ (1:100, Alomone, Labs, Jerusalem, Israel) primary antibody and co-labeled with mouse monoclonal Anti-alpha smooth muscle Actin antibody (1:200, Abcam, Cambrige, UK) overnight. The next day, primary antibodies were removed, and the samples were incubated with secondary antibodies for $2 \mathrm{~h}$ (FITC anti-rabbit, 1:100, Abcam (Cambrige, UK); and Alexa Fluor-568 anti-mouse, 1:50, Thermo Fisher Scientific, Waltham, MA, USA). Nuclei were counterstained with DAPI. Then a coverslip was placed using an antifade reagent (Prolong Diamond Antifade, Invitrogen, Waltham, MA, USA). Finally, images were acquired using a confocal microscope (Mod LSM 700, Zeiss), 3-D blind deconvolved (AutoQuant X3, Media Cybernetics), and subsequently analyzed with ZEN2009 (Zeiss), and Image J software (National Institutes of Health, Bethesda, ML, USA). 


\subsection{Vascular Contractility}

It is well documented that the cannabinoid receptors participate in the regulation of blood pressure at the vascular level. Therefore, to know if treatment with ZnONPs modifies the contractility at this level, the effects of selective agonists for both receptors, $\mathrm{CB}_{1}$ and $\mathrm{CB}_{2}$, on aorta contractility were evaluated in vitro. For these experiments, the following protocol was carried out: aortic rings approximately $2 \mathrm{~mm}$ wide were mounted in an isolated organ bath filled with Krebs-Henseleit solution (KHS) bubbled with carbogen $\left(95 \% \mathrm{O}_{2}, 5 \% \mathrm{CO}_{2}\right)$. The ring was then fixed between two stainless steel wires, one of them coupled to an isometric force transducer (Radnoti) whose signal was amplified (CyberAmp 380, Axon instruments inc., Foster City, CA, USA) and digitized by an analog-digital interface (Digidata 1200, Axon instruments inc., Foster City, CA, USA). The initial tension of the ring was adjusted to $2 \mathrm{~g}$ and stabilized for $60 \mathrm{~min}$. Then a contracture was generated with phenylephrine $(1 \mu \mathrm{M})$ reaching its maximum response after approximately $15 \mathrm{~min}$. At this point, the effect of the agonists ACPA $30 \mu \mathrm{M}$ (selective for $\mathrm{CB}_{1}$ receptor) or HU308 $10 \mu \mathrm{M}$ (selective for $\mathrm{CB}_{2}$ receptor) on tension was evaluated. The tension records were acquired and analyzed with Axoscope and Clampfit software (Version 9, Axon Instruments Inc., Foster City, CA, USA), respectively.

The bath temperature was kept constant at $37^{\circ} \mathrm{C}$ for the duration of the experiment. The composition of the $\mathrm{KH}$ solution was the following (in $\mathrm{mM}$ ): $118 \mathrm{NaCl}, 5 \mathrm{KCl}, 1.2 \mathrm{MgSO}_{4}$, $1.2 \mathrm{KH}_{2} \mathrm{PO}_{4}, 25 \mathrm{NaHCO}_{3}, 2 \mathrm{CaCl}_{2}$, added with $2 \mathrm{~g}$ D-Glucose, $\mathrm{pH}$ 7.4.

\subsection{Statistical Analysis}

Data were expressed as means \pm standard error. The experimental groups were analyzed using a one-way analysis of variance and the comparison between pairs of groups was performed with the Bonferroni test. The differences were considered significant with $p<0.05$. All the processing and statistical analyses of the data were carried out with GraphPad Prism 8 software.

\section{Results}

\subsection{Effects of the ZnONPs on Lipid Profile and Atherogenic Risk}

The treatment with ZnONPs did not alter total cholesterol and serum HDL-C in healthy rats in the first 2 months. However, three months later, the total cholesterol and HDL-C increased significantly to $29 \%$ and $81 \%$ respectively compared to the control group (Table 1). ZnONPs decreased LDL-C concentration, an effect that was significant at the first $(49 \%)$ and third month $(26 \%)$ of the treatment compared to the control group. With respect to triglycerides concentration, the treatment significantly increased its levels after one (50\%) and two months (34\%) compared to the control. Finally, the atherogenic risk with the treatment of $\mathrm{ZnONPs}$ increased significantly only in the first month (240\%) compared to the control group (Table 1).

Table 1. Lipid profile and atherosclerosis risk.

\begin{tabular}{cccccc}
\hline $\begin{array}{c}\text { Experimental } \\
\text { Group }\end{array}$ & $\begin{array}{c}\text { Total } \\
\text { Cholesterol } \\
\mathbf{m g} / \mathbf{d L}\end{array}$ & $\begin{array}{c}\text { HDL-C } \\
\mathbf{m g} / \mathbf{d L}\end{array}$ & $\begin{array}{c}\text { LDL-C } \\
\mathbf{m g} / \mathbf{d L}\end{array}$ & $\begin{array}{c}\text { Triglycerides } \\
\mathbf{m g} / \mathbf{d L}\end{array}$ & $\begin{array}{c}\text { Atherogenic } \\
\text { Index }\end{array}$ \\
\hline $\begin{array}{c}\text { Control } \\
\text { ZnONPs- } \\
1 \text { month }\end{array}$ & $52 \pm 2$ & $23 \pm 2$ & $38 \pm 3$ & $32 \pm 2$ & $0.14 \pm 0.04$ \\
$\begin{array}{l}\text { ZnONPs- } \\
2 \text { moths }\end{array}$ & $56 \pm 3$ & $21 \pm 1$ & $19 \pm 2^{\mathrm{a}}$ & $48 \pm 3^{\mathrm{a}}$ & $0.34 \pm 0.04^{\mathrm{a}}$ \\
$\begin{array}{l}\text { ZnONPs- } \\
3 \text { months }\end{array}$ & $67 \pm 6^{\mathrm{a}}$ & $40 \pm 2^{\mathrm{a}}$ & $29 \pm 3^{\mathrm{a}}$ & $31 \pm 1$ & $0.00 \pm 0.11$ \\
\hline
\end{tabular}




\subsection{Effect of the ZnONPs Treatment on the Structure of the Aorta Wall}

The first parameter evaluated was the thickness of the aorta wall. The thickness significantly increased since the first month of the treatment and was maintained for three months as shown in Figures 1 and 2.

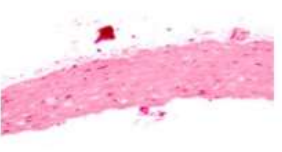

$\frac{100 \mu \mathrm{m}}{\text { Scale ba }}$

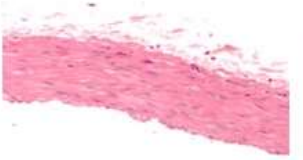

(b)

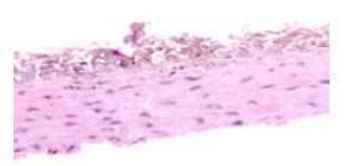

(c)

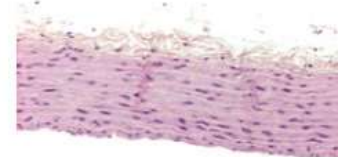

(d)

Figure 1. Representative images of aorta sections stained with hematoxylin-eosin. (a) control or healthy rat, (b) ZnONPs-One month treated rat, (c) ZnONPs-Two months treated rat, and (d) ZnONPsThree months treated rat. All images were acquired with $10 \times$ magnification.

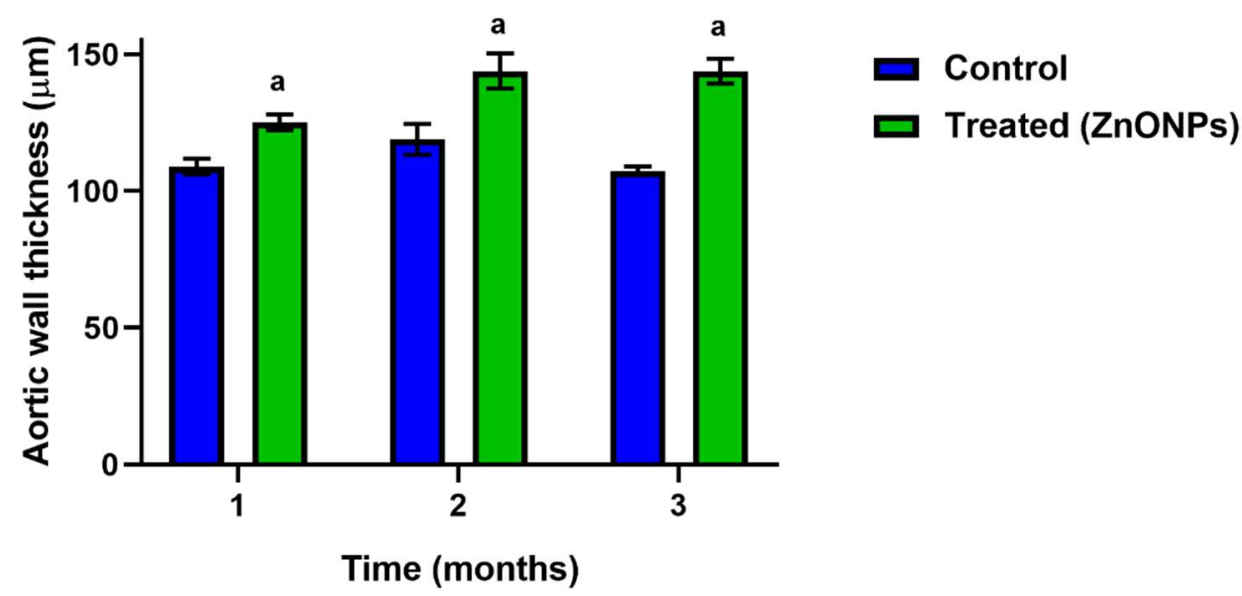

Figure 2. Effect of ZnONPs on the aortic wall thickness. Blue bars correspond to the control nontreated group; green bars correspond to the ZnONPs treated-groups at different times. a, there is a significant difference compared to the control group with $p<0.05$.

The histological analysis in the slides stained with hematoxylin-eosin did not reveal differences in the first month of the treatment, foam cells and normal cholesterol drops were observed in both groups, control and treated (Figure 3a,b). Furthermore, in the second month, a greater accumulation of intracellular lipids was distinguished in the rats treated with ZnONPs, and in the third month, extracellular lipid deposits and fatty streaks were detected in the treated group (Figure $3 c, d$ ). The structural characteristics observed in the rat aorta after two or three months of the treatment with ZnONPs are typical in the atherosclerotic process.

\subsection{Alterations in ZnONPs-Induced Vascular Contractility}

ACPA $\left(\mathrm{CB}_{1}\right.$ receptor agonist) induced $20 \%$ vasorelaxation in the aorta of untreated rats (Figure 4a). Interestingly, ACPA in the aorta of rats that received ZnONPs for one month had no effect on the vascular tension. The treatment attenuated the vasorelaxation observed in control rats. At a treatment longer time with $\mathrm{ZnONPs}$, ACPA induced vasoconstriction, $11 \%$ at two months and $16 \%$ at the end of the third month (Figure $4 a$ ). 


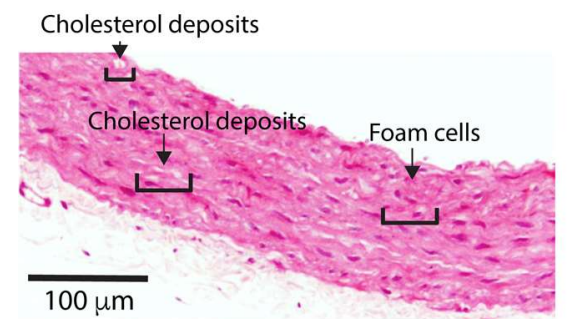

(a)

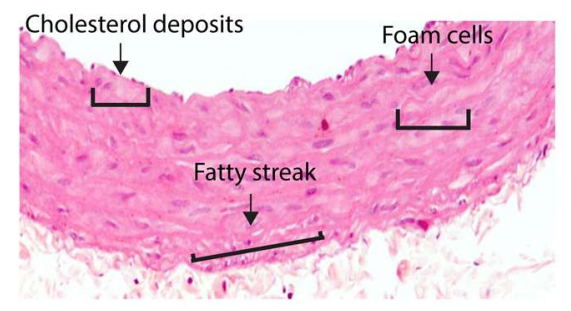

(c)

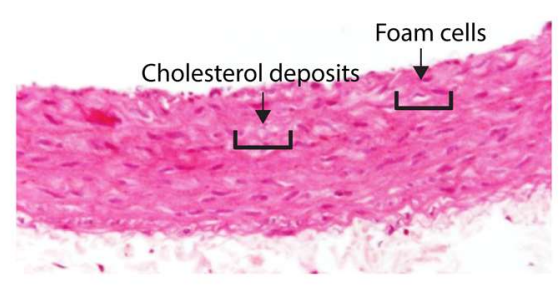

(b)

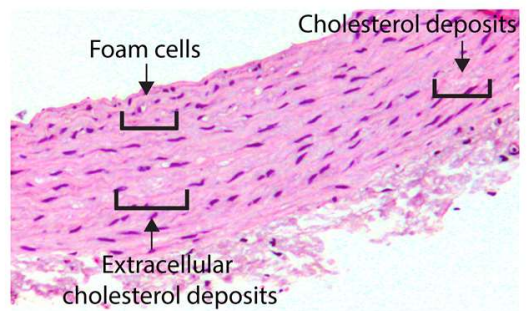

(d)

Figure 3. Illustrative images showing atherosclerotic lesions after of the treatment with ZnONPs: (a) control or healthy rat, (b) ZnONPs-1 month treated rat, (c) ZnONPs-2 months treated rat, and (d) ZnONPs-3 months treated rat. All images were acquired with $10 \times$ magnification.

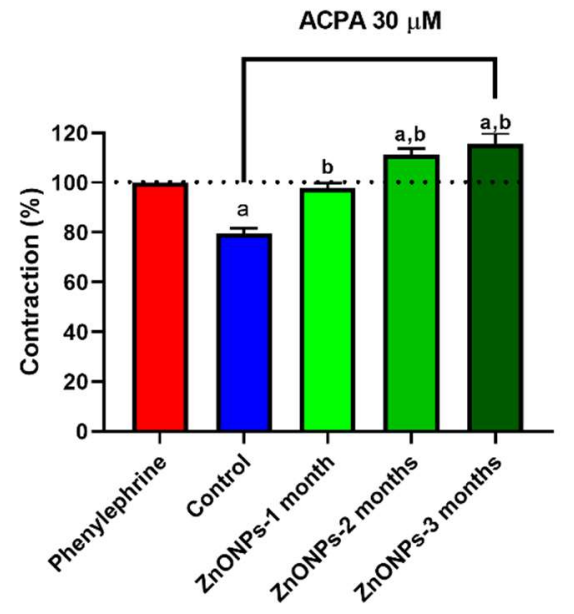

(a)

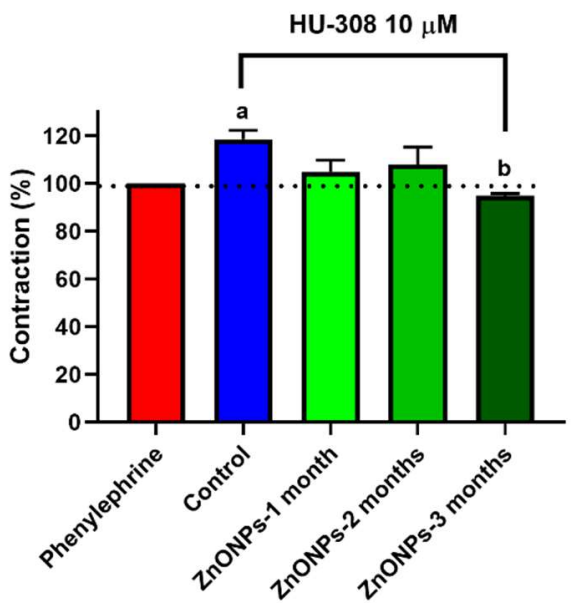

(b)

Figure 4. Effect of ZnONPs on aorta contractility. (a) Effect of $\mathrm{ACPA}\left(\mathrm{CB}_{1}\right.$ receptor agonist) on contraction in aortic rings in different experimental groups. (b) Effect of HU308 $\left(\mathrm{CB}_{2}\right.$ receptor agonist) on contraction in aortic rings in different experimental groups. Blue bars correspond to the control non-treated group, green bars correspond to the ZnONPs treated-groups at different times; (a) there is a significant difference compared to the phenylephrine group with $p<0.05$; (b) there is a significant difference compared to the control group with $p<0.05$.

When HU308 ( $\mathrm{CB}_{2}$ receptor agonist) was evaluated on aorta contractile activity, a vasoconstrictor effect (19\%) was observed in untreated rats. In ZnONPs-treated rats, the vasoconstriction effect HU308 was lower than that observed in untreated rats. The vasoconstriction was not statistically significant in the first two months. After the third month, the vasoconstriction was completely abolished, and 5\% vasorelaxation was even observed (Figure 4 b). 


\section{4. $C B_{1}$ and $C B_{2}$ Receptors Expression in Aorta Rings of ZnONPs-Treated Rats}

To determine the expression of cannabinoid receptors in the aorta, the mean fluorescence intensity was quantified, and results were normalized concerning the control group that did not receive $\mathrm{ZnONPs}$ treatment. The first month of treatment with ZnONPs did not alter the expression of the $\mathrm{CB}_{1}$ receptor in the aorta wall (Figure 5a).

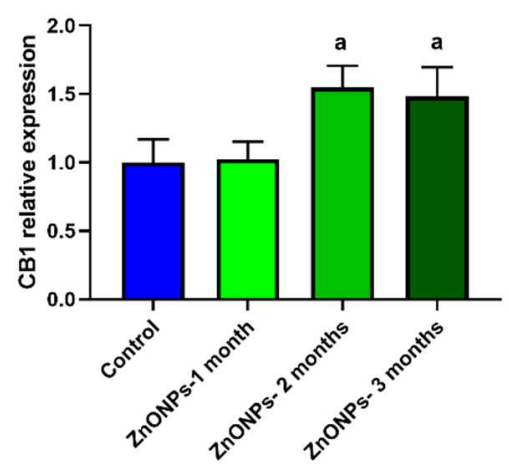

(a)

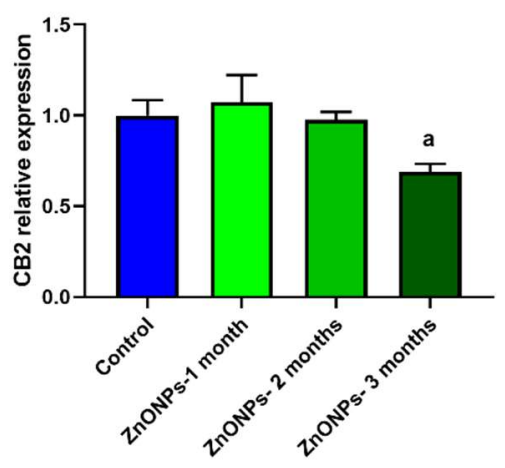

(b)

Figure 5. Effect of ZnONPs on the $\mathrm{CB}_{1}$ and $\mathrm{CB}_{2}$ receptors expression in the aorta wall. (a) $\mathrm{CB}_{1}$ expression, (b) $\mathrm{CB}_{2}$ expression. Blue bars correspond to the control non-treated group, green bars correspond to the ZnONPs treated-groups at different times; (a) there is a significant difference compared to the control group with $p<0.05$.

In contrast, after two and three months, the expression significantly increased, approximately $50 \%$ in comparison to the control group (Figure $5 \mathrm{a}$ ). In the case of the $\mathrm{CB}_{2}$ receptor, ZnONPs did not modify the expression during the first two months of treatment, while after three months, the expression decreased significantly by $31 \%$ compared to the control group (Figure 5b) (See illustrative images in Figure 6).

\subsection{ZnONPs on Blood Pressure}

Systolic blood pressure (SBP) is a parameter used for the diagnosis of arterial hypertension. In this study, the oral administration of ZnONPs in healthy rats significantly increased SBP $(18 \%)$ after three months in compared to the non-treated control group as shown in Table 2.

Table 2. Effects of oral administration of ZnONPs on systolic blood pressure in healthy rats.

\begin{tabular}{cccc}
\hline \multicolumn{3}{c}{ Systolic Blood Pressure (mmHg) } \\
\hline Control & Rats treated with ZnONPs & \\
& One-month & Two-months & Three-months \\
$116 \pm 3$ & $125 \pm 9$ & $129 \pm 4$ & $137 \pm 4^{\text {a }}$ \\
\hline
\end{tabular}

a There is a significant difference compared to the control group with $p<0.05$. 

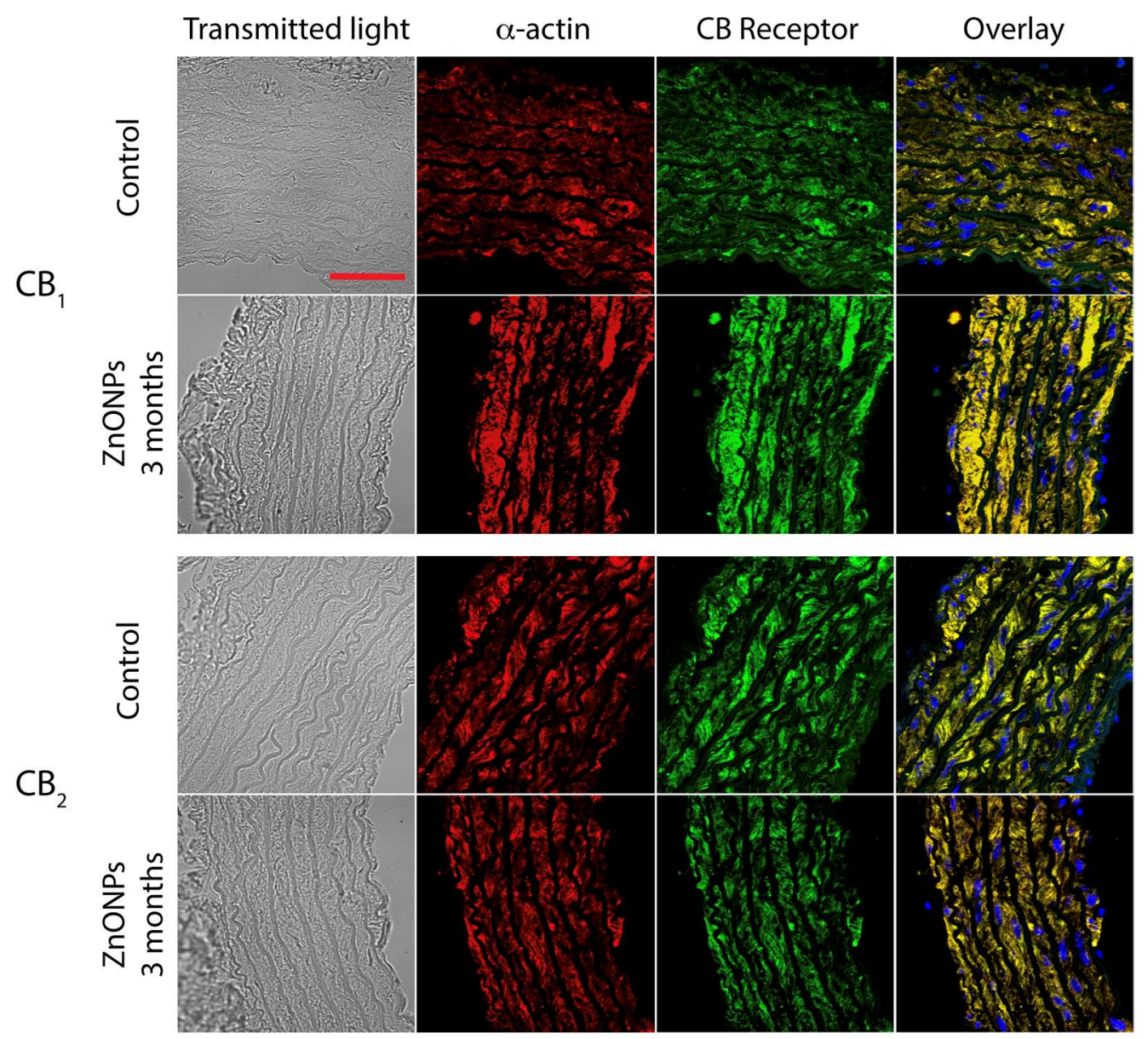

Figure 6. Representative images showed $\mathrm{ZnONPs}$ effect on $\mathrm{CB}_{1}$ and $\mathrm{CB}_{2}$ receptors expression in aorta wall. Transmitted light images (grey). Scale bar corresponds to $50 \mu \mathrm{m}$. Smooth muscle $\alpha$-actin was detected with a specific antibody labeled with Alexa Fluor 568 (red). $\mathrm{CB}_{1}$ and $\mathrm{CB}_{2}$ located on the aorta ring were detected by specific antibodies and labeled with FITC (green). Image overlap indicates a high degree of colocalization of $\mathrm{CB}_{1}$ or $\mathrm{CB}_{2}$, and smooth muscle $\alpha$-actin (yellow). Nuclei were counterstained with DAPI dye (blue).

\section{Discussion}

In the present study, the effects of the long-term oral administration of ZnONPs $(10 \mathrm{mg} / \mathrm{kg})$ on lipid profile, blood pressure, vascular structure, and contractility, as well as on the expression of $C_{1}$ and $C_{2}$ cannabinoid receptors in healthy rats, were evaluated.

The results of the present research showed that $\mathrm{ZnONPs}$ induce changes in the serum lipid profile. They mainly increase triglycerides during the first two months of the treatment and total cholesterol and HDL-C after three months (Table 1). In addition, a high atherogenic risk was observed after one month of treatment. In the literature $[13,20,21]$, it has been reported that ZnONPs induce lipid alterations depending on the dose or concentration, the administration route, and the exposure time. Intratracheal administration of ZnONPs $(1.25-5 \mathrm{mg} / \mathrm{kg})$ in rats for 12 weeks induced an increase in TC and LDL-C and a decrease in HDL-C, dependent on the concentration [13]. In another study also carried out in rats, after 2 weeks of administration (25-50 mg/ kg) TG increased, and HDL-L and LDL-C decreased in a dose-dependent manner [20]. In healthy mice that received ZnONPs orally (333 mg $/ \mathrm{kg}$, 5 days), TG increased and both HDL-C and LDL-C decreased [21]. In contrast to the dyslipidemia observed in healthy subjects, recent studies reported that ZnONPs (5-10 mg/kg) decreased serum TC and TG in rats with hepatocellular carcinoma, improving their lipid metabolism [22], while in diabetic rats, ZnONPs at $3 \mathrm{mg} / \mathrm{kg}$ decreased TC, increased HDL-C and reduced the risk of atherosclerosis [14]. In general, 
dyslipidemia observed in healthy subjects increases atherogenic and cardiovascular risk. Increased atherogenic index the first month of the treatment in our experiments agree with other authors [13] and contrasts with another study that did not observe changes in the atherosclerosis development risk [14]. It is also important to say that although some genetic and molecular studies report homologies between cholesterol-transport lipoproteins in mice and humans [23,24], other studies have reported differences between rodents and humans in the lipid metabolism. While in humans LDL-C is the main responsible for the transport of cholesterol, in mice and rats it has been suggested that it is HDL-C [25,26]. These differences could help to improve the understanding of what was observed in our study where both total cholesterol and HDL-C increase in the second month and these differences become significant in the third month, which is consistent with the atherosclerotic alterations observed in the histological analysis. However, more studies are needed to understand the metabolic and functional implications of these reported differences between rodents and humans in the lipid metabolism.

We were also interested to know if this dyslipidemia induced by ZnONPs also elicited changes in the vascular structure. Our results showed that aorta wall thickness increased (Figures 1 and 2), an observation that agrees with a previous study [13]. In addition, the results of the histological analysis revealed the formation of fatty streaks in the aorta wall (Figure 3), lesions that are very common of the atherosclerosis process. Our results support previous observations made in in vitro assays which suggest that ZnONPs can induce atherosclerosis and increase cardiovascular risk through an inflammatory mechanism $[13,27,28]$, mediated by the formation of reactive oxygen species, ROS [29-31], and zinc ions playing a key role [32]. However, investigation to study the effects of ZnONPs at a dose of $10 \mathrm{mg} / \mathrm{kg}$ on oxidative stress and vascular inflammation in rats is needed.

This study is the first to analyze the effects of the ZnONPs chronic administration on the contractile activity in aortic rings (Figure 4). These assays are widely used to understand the mechanisms that regulate systemic blood pressure. Vasorelaxation contributes to a decrease in the blood pressure and vasoconstriction contributes to an increase in blood pressure. The balance of both processes determines systemic blood pressure. It is well documented that the endocannabinoid system plays an important role in the regulation of the blood pressure and cardiovascular diseases. Activation of the $\mathrm{CB}_{1}$ receptor, with agonists such as anandamide, induces vasorelaxation $[33,34]$ and a decrease in the blood pressure in normotensive and hypertension models $[35,36]$. Blockade of the $\mathrm{CB}_{1}$ receptor decreases the atherosclerosis risk while activation of the $\mathrm{CB}_{2}$ receptor decreases the progression of the atherosclerosis acting as a cardioprotective agent [37-41]. Furthermore, increased $\mathrm{CB}_{1}$ receptor expression has been associated with vascular smooth muscle cell proliferation and atherosclerosis [42,43]. ACPA, a selective $\mathrm{CB}_{1}$ receptor agonist, has been reported to induce aortic vasorelaxation in previous studies [44]. In the present study, the treatment with ZnONPs modified the ACPA-induced vasorelaxation response even eliciting vasoconstriction (Figure 4a). Phenylephrine-induced vascular contraction is known to be mediated by mechanisms that allow calcium influx into smooth muscle cells through of calcium channels and other transporters [45]. ACPA has previously been reported to induce vasorelaxation through a mechanism mediated by activation of the calcium activated potassium channel subunit alpha- $1\left(\mathrm{~K}_{\mathrm{Ca}} 1.1\right)$ and blocking of the calcium channel, voltage-dependent, $\mathrm{L}$ type, alpha $1 \mathrm{C}$ subunit $\left(\mathrm{Ca}_{\mathrm{v}} 1.2\right)$ [44]. It has also been reported in other cells that ZnONPs increase the concentration of cytosolic calcium through a mechanism mediated by L-type calcium channel activation [46], and this effect could be inhibiting the vasorelaxation induced by ACPA seen in control conditions. Thus, ZnONPs could be eliciting vasoconstriction through of L-type calcium channels activation, allowing calcium influx into the cell. Additionally, it has also been reported that ZnONPs can induce endothelial dysfunction [47], which means it is possible that the ZnONPs are also impairing the mechanism of synthesis and release of nitric oxide (NO) at endothelial level which play a key role in the vasorelaxation [48]. The above mechanisms could be a possible explanation for the fact that ACPA did not increase vasorelaxation despite the increase 
in the $\mathrm{CB}_{1}$ receptors expression induced by ZnONPs (Figures 5a and 6). In the case of $\mathrm{HU} 308$, a selective $\mathrm{CB}_{2}$ receptor agonist elicited vasoconstriction in healthy rats, while in $\mathrm{ZnONPs}$-treated rats the vasoconstrictor response was completely abolished . Little is known about the mechanism through which $\mathrm{H} 308$ modulates vascular tone through the $\mathrm{CB}_{2}$ receptor. A study carried out in a cell line with high expression of the $C_{2}$ receptor showed that HU308 increases cytosolic calcium by two mechanisms: one acting at the level of reservoirs such as sarcoplasmic reticulum increasing the release of calcium, and another by activation of calcium channels in the cell membrane mediated by $\mathrm{G}$ coupled receptors (G $\alpha \mathrm{q} / 11)$, and phospholipase C (PLC) way [49]. These mechanisms that increase the availability of cytosolic calcium could be responsible for the vasoconstriction effect of HU308 observed in our experiments, and if this mechanism were responsible, then the decrease in the expression of $\mathrm{CB}_{2}$ receptors shown in this study (Figure $5 b$ ) could be associated with the reduction of vasoconstriction observed in the aorta of rats treated with ZnONPs. However, future studies are necessary to elucidate these mechanisms in this artery.

ZnONPs increased $\mathrm{CB}_{1}$ receptors expression and decreased $\mathrm{CB}_{2}$ receptor expression in the aorta wall (Figure 5). At present, it is debated whether the expression of these receptors is correlated with the progress of atherosclerosis, specifically the $\mathrm{CB}_{1}$ receptor as atherogenic and the $\mathrm{CB}_{2}$ receptor as atheroprotective [15-18,42,43]. Our study shows a correlation of increased expression of the $\mathrm{CB}_{1}$ receptor and decreased $\mathrm{CB}_{2}$ receptor with the development of atherosclerosis. However, future studies are needed to elucidate the molecular signaling mechanism by which increased expression of the $\mathrm{CB}_{1}$ receptor induces atherosclerosis.

Finally, the current study shows that ZnONPs induced an increase in the systolic blood pressure in healthy rats. To our knowledge, it is the first report of this effect. Some studies have analyzed the effect of ZnONPs on cardiovascular function but not on blood pressure [50-53]. In a clinical trial, healthy adults were exposed to inhalation of ZnONPs for a short period and no effects were found on heart rate and electrocardiographic patterns [50]. In contrast, in isolated cardiomyocytes, $\mathrm{ZnONPs}$ induce some electrophysiological alterations such as a decrease in beat rate and spike amplitude [51]. Moreover, it is known that atherosclerosis is associated with increased blood pressure $[52,53]$.

\section{Conclusions}

Chronic administration of $\mathrm{ZnO}$ nanoparticles by oral route induced dyslipidemia and atherosclerotic lesions, which was accompanied by alterations at the structural level, $\mathrm{CB}_{1}$ and $\mathrm{CB}_{2}$ receptor expression, vascular contractility, and increased blood pressure. ZnONPsinduced atherosclerosis is associated with increased expression of the $\mathrm{CB}_{1}$ receptor and decreased expression of the $\mathrm{CB}_{2}$ receptor in the aorta wall.

Author Contributions: Conceptualization and design, A.V.-O. and E.S.-P.; methodology, A.C.-G., M.d.R.Á.-V., A.F.-G. and A.R.-H.; software, A.C.-G., M.d.R.Á.-V. and A.F.-G.; formal analysis, A.C.-G., S.L.-M., F.A. and I.D.-R.; investigation, A.C.-G., A.R.-H., S.L.-M., F.A. and I.D.-R.; data curation, A.C.-G. and A.A.-I.; writing—original draft preparation, A.V.-O.; writing-review and editing, E.S.-P., A.A.-I., L.C.-S. and J.A.; supervision, A.V.-O.; project administration, E.S.-P.; funding acquisition, E.S.-P. All authors have read and agreed to the published version of the manuscript.

Funding: This research was funded by Conacyt-México to Sánchez-Pastor (Grant number A1-S13192).

Institutional Review Board Statement: This study was revised and approved by the bioethics committee of the University Center for Biomedical Research of the University of Colima (Project code 2020-1; approval date: 12 February 2020).

Informed Consent Statement: Not applicable.

Data Availability Statement: Data are contained within the article.

Conflicts of Interest: The authors declare no conflict of interest. 


\section{References}

1. Gudkov, S.V.; Burmistrov, D.E.; Serov, D.A.; Rebezov, M.B.; Semenova, A.A.; Lisitsyn, A.B.A. Mini Review of Antibacterial Properties of ZnO Nanoparticles. Front. Phys. 2021, 9, 641481. [CrossRef]

2. Nazarizadeh, A.; Asri-Rezaie, S. Comparative Study of Antidiabetic Activity and Oxidative Stress Induced by Zinc Oxide Nanoparticles and Zinc Sulfate in Diabetic Rats. AAPS PharmSciTech 2016, 17, 834-843. [CrossRef] [PubMed]

3. Alkaladi, A.; Abdelazim, A.M.; Afifi, M. Antidiabetic activity of zinc oxide and silver nanoparticles on streptozotocin-induced diabetic rats. Int. J. Mol. Sci. 2014, 15, 2015-2023. [CrossRef] [PubMed]

4. Umrani, R.D.; Paknikar, K.M. Zinc oxide nanoparticles show antidiabetic activity in streptozotocin-induced Type 1 and 2 diabetic rats. Nanomedicine 2014, 9, 89-104. [CrossRef]

5. Alomari, G.; Al-Trad, B.; Hamdan, S.; Aljabali, A.A.A.; Al Zoubi, M.S.; Al-Batanyeh, K.; Qar, J.; Eaton, G.J.; Alkaraki, A.K.; Alshaer, W.; et al. Alleviation of diabetic nephropathy by zinc oxide nanoparticles in streptozotocin-induced type 1 diabetes in rats. IET Nanobiotechnol. 2021, 15, 473-483. [CrossRef]

6. Afifi, M.; Almaghrabi, O.A.; Kadasa, N.M. Ameliorative Effect of Zinc Oxide Nanoparticles on Antioxidants and Sperm Characteristics in Streptozotocin-Induced Diabetic Rat Testes. BioMed Res. Int. 2015, 2015, 153573. [CrossRef]

7. Shanker, K.; Naradala, J.; Mohan, G.K.; Kumar, G.S.; Pravallika, P.L. A sub-acute oral toxicity analysis and comparative in vivo anti-diabetic activity of zinc oxide, cerium oxide, silver nanoparticles, and Momordica charantia in streptozotocin-induced diabetic Wistar rats. RSC Adv. 2017, 7, 37158-37167. [CrossRef]

8. Kong, T.; Zhang, S.H.; Zhang, J.L.; Hao, X.Q.; Yang, F.; Zhang, C.; Yang, Z.J.; Zhang, M.Y.; Wang, J. Acute and Cumulative Effects of Unmodified 50-nm Nano-ZnO on Mice. Biol. Trace Elem. Res. 2018, 185, 124-134. [CrossRef]

9. Hong, T.K.; Tripathy, N.; Son, H.J.; Ha, K.T.; Jeong, H.S.; Hahn, Y.B. A comprehensive in vitro and in vivo study of ZnO nanoparticles toxicity. J. Mater. Chem. B 2013, 1, 2985-2992. [CrossRef] [PubMed]

10. Park, H.S.; Kim, S.J.; Lee, T.J.; Kim, G.Y.; Meang, E.; Hong, J.S.; Kim, S.H.; Koh, S.B.; Hong, S.G.; Sun, Y.S.; et al. A 90-day study of sub-chronic oral toxicity of $20 \mathrm{~nm}$ positively charged zinc oxide nanoparticles in Sprague Dawley rats. Int. J. Nanomed. 2014, 9 , 93-107.

11. Liu, H.; Yang, H.; Fang, Y.; Li, K.; Tian, L.; Liu, X.; Zhang, W.; Tan, Y.; Lai, W.; Bian, L.; et al. Neurotoxicity and biomarkers of zinc oxide nanoparticles in main functional brain regions and dopaminergic neurons. Sci. Total Environ. 2020, 705, 135809, Erratum in: Sci. Total Environ. 2021, 765, 145120. [CrossRef] [PubMed]

12. Guo, Z.; Zhang, P.; Luo, Y.; Xie, H.Q.; Chakraborty, S.; Monikh, F.A.; Lynch, I. Intranasal exposure to ZnO nanoparticles induces alterations in cholinergic neurotransmission in rat brain. Nano Today 2020, 35, 100977. [CrossRef]

13. Yan, Z.; Wang, W.; Wu, Y.; Wang, W.; Li, B.; Liang, N.; Wu, W. Zinc oxide nanoparticle-induced atherosclerotic alterations in vitro and in vivo. Int. J. Nanomed. 2017, 12, 4433-4442. [CrossRef]

14. Asri-Rezaei, S.; Dalir-Naghadeh, B.; Nazarizadeh, A.; Noori-Sabzikar, Z. Comparative study of cardio-protective effects of zinc oxide nanoparticles and zinc sulfate in streptozotocin-induced diabetic rats. J. Trace Elem. Med. Biol. 2017, 42, 129-141. [CrossRef]

15. Fulmer, M.L.; Thewke, D.P. The Endocannabinoid System and Heart Disease: The Role of Cannabinoid Receptor Type 2. Cardiovasc. Hematol. Disord. Drug Targets 2018, 18, 34-51. [CrossRef] [PubMed]

16. Singla, S.; Sachdeva, R.; Mehta, J.L. Cannabinoids and Atherosclerotic Coronary Heart Disease. Clin Cardiol 2012, 35, 329-335. [CrossRef] [PubMed]

17. Guillamat-Prats, R.; Rami, M.; Herzig, S.; Steffens, S. Endocannabinoid Signalling in Atherosclerosis and Related Metabolic Complications. Thromb. Haemost. 2019, 119, 567-575. [CrossRef]

18. Turcotte, C.; Blanchet, M.R.; Laviolette, M.; Flamand, N. The CB22 receptor and its role as a regulator of inflammation. Cell. Mol. Life Sci. 2016, 73, 4449-4470. [CrossRef] [PubMed]

19. Virgen-Ortiz, A.; Apolinar-Iribe, A.; Díaz-Reval, I.; Parra-Delgado, H.; Limón-Miranda, S.; Sánchez-Pastor, E.A.; Castro-Sánchez, L.; Jesús Castillo, S.; Dagnino-Acosta, A.; Bonales-Alatorre, E.; et al. Zinc Oxide Nanoparticles Induce an Adverse Effect on Blood Glucose Levels Depending on the Dose and Route of Administration in Healthy and Diabetic Rats. Nanomaterials 2020, 10, 2005. [CrossRef]

20. Pour-Mohammad, P.; Alipanah-Moghadam, R.; Amani, F.; Nemati, A.; Malekzadeh, V. Effect of Zinc Oxide Nanoparticles on Blood Lipid Profile in Wistar Male Rats. J. Ardabil. Univ. Med. Sci. 2018, 18, 34-42. [CrossRef]

21. Esmaeillou, M.; Moharamnejad, M.; Hsankhani, R.; Tehrani, A.A.; Maadi, H. Toxicity of ZnO nanoparticles in healthy adult mice. Environ. Toxicol. Pharmacol. 2013, 35, 67-71. [CrossRef] [PubMed]

22. Bashandy, S.A.E.; Ahmed-Farid, O.A.H.; Abdelmottaleb-Moussa, S.; Omara, E.A.; Abdel Jaleel, G.A.; Ibrahim, F.A.A. Efficacy of zinc oxide nanoparticles on hepatocellular carcinomainduced biochemical and trace element alterations in rats. J. Appl. Pharm. Sci 2021, 11, 108-117.

23. Gordon, S.M.; Li, H.; Zhu, X.; Shah, A.S.; Lu, L.J.; Davidson, W.S. A comparison of the mouse and human lipoproteome: Suitability of the mouse model for studies of human lipoproteins. J. Proteome Res. 2015, 14, 2686-2695. [CrossRef] [PubMed]

24. Wang, X.; Paigen, B. Genetics of variation in HDL cholesterol in humans and mice. Circ. Res. 2005, 96, 27-42. [CrossRef] [PubMed]

25. Zhao, Y.; Qu, H.; Wang, Y.; Xiao, W.; Zhang, Y.; Shi, D. Small rodent models of atherosclerosis. Biomed. Pharmacother. 2020, 129, 110426. [CrossRef] [PubMed]

26. Leong, X.F.; Ng, C.Y.; Jaarin, K. Animal Models in Cardiovascular Research: Hypertension and Atherosclerosis. BioMed Res. Int. 2015, 2015, 528757. [CrossRef] 
27. Gojova, A.; Guo, B.; Kota, R.S.; Rutledge, J.C.; Kennedy, I.M.; Barakat, A.I. Induction of inflammation in vascular endothelial cells by metal oxide nanoparticles: Effect of particle composition. Environ. Health Perspect. 2007, 115, 403-409. [CrossRef]

28. Li, C.H.; Liao, P.L.; Shyu, M.K.; Liu, C.W.; Kao, C.C.; Huang, S.H.; Kang, J.J. Zinc Oxide Nanoparticles-Induced Intercellular Adhesion Molecule 1 Expression Requires Rac1/Cdc42, Mixed Lineage Kinase 3, and c-Jun N-Terminal Kinase Activation in Endothelial Cells. Toxicol. Sci. 2012, 126, 162-172. [CrossRef]

29. Sun, J.; Wang, S.; Zhao, D.; Hun, F.H.; Weng, L.; Liu, H. Cytotoxicity, permeability, and inflammation of metal oxide nanoparticles in human cardiac microvascular endothelial cells. Cell Biol. Toxicol. 2011, 27, 333-342. [CrossRef]

30. Akhtar, M.J.; Ahamed, M.; Alhadlaq, H. Gadolinium Oxide Nanoparticles Induce Toxicity in Human Endothelial HUVECs via Lipid Peroxidation, Mitochondrial Dysfunction and Autophagy Modulation. Nanomaterials 2020, 10, 1675. [CrossRef]

31. Qin, X.; Zhang, J.; Wang, B.; Xu, G.; Yang, X.; Zou, Z.; Yu, C. Ferritinophagy is involved in the zinc oxide nanoparticles-induced ferroptosis of vascular endothelial cells. Autophagy 2021, 1, 20.

32. Yeh, S.C.; Tsai, F.Y.; Chao, H.R.; Tsou, T.C. Zinc Ions Induce Inflammatory Responses in Vascular Endothelial Cells. Bull. Environ. Contam. Toxicol. 2011, 87, 113-116. [CrossRef]

33. White, R.; Ho, W.S.; Bottrill, F.E.; Ford, W.R.; Hiley, C.R. Mechanisms of anandamide-induced vasorelaxation in rat isolated coronary arteries. Br. J. Pharmacol. 2001, 134, 921-929. [CrossRef]

34. Mukhopadhyay, S.; Chapnick, B.M.; Howlett, A.C. Anandamide-induced vasorelaxation in rabbit aortic rings has two components: G protein dependent and independent. Am. J. Physiol. Heart Circ. Physiol. 2002, 282, H2046-H2054. [CrossRef] [PubMed]

35. Lake, K.D.; Martin, B.R.; Kunos, G.; Varga, K. Cardiovascular effects of anandamide in anesthetized and conscious normotensive and hypertensive rats. Hypertension 1997, 29, 1204-1210. [CrossRef]

36. Varga, K.; Lake, K.D.; Huangfu, D.; Guyenet, P.G.; Kunos, G. Mechanism of the hypotensive action of anandamide in anesthetized rats. Hypertension 1996, 28, 682-686. [CrossRef]

37. Mach, F.; Steffens, S. The Role of the Endocannabinoid System in Atherosclerosis. J. Neuroendocrinol. 2008, 20, 53-57. [CrossRef] [PubMed]

38. Maslov, L.N.; Karpov, R.S. Prospects for the use of cannabinoid receptor ligands for the treatment of metabolic syndrome and atherosclerosis: Analysis of experimental and clinical data. Vestn. Ross. Akad. Med. Nauk. 2017, 72, 59-65. [CrossRef] [PubMed]

39. Wu, A.; Hu, P.; Lin, J.; Xia, W.; Zhang, R. Activating Cannabinoid Receptor 2 Protects Against Diabetic Cardiomyopathy Through Autophagy Induction. Front. Pharmacol. 2018, 9, 1292. [CrossRef] [PubMed]

40. van Eenige, R.; Ying, Z.; Tambyrajah, L.; Pronk, A.C.M.; Blomberg, N.; Giera, M.; Wang, Y.; Coskun, T.; van der Stelt, M.; Rensen, P.C.N.; et al. Cannabinoid type 1 receptor inverse agonism attenuates dyslipidemia and atherosclerosis in APOE $* 3$-Leiden.CETP mice. J. Lipid Res. 2021, 62, 100070. [CrossRef] [PubMed]

41. Pacher, P. Cannabinoid CB1 receptor antagonists for atherosclerosis and cardiometabolic disorders: New hopes, old concerns? Arterioscler. Thromb. Vasc. Biol. 2009, 29, 7-9. [CrossRef]

42. Pacher, P.; Steffens, S. The emerging role of the endocannabinoid system in cardiovascular disease. Semin. Immunopathol. 2009, 31, 63-77. [CrossRef]

43. Alfulaij, N.; Meiners, F.; Michalek, J.; Small-Howard, A.L.; Turner, H.C.; Stokes, A.J. Cannabinoids, the Heart of the Matter. J. Am. Heart Assoc. 2018, 7, e009099. [CrossRef]

44. Sánchez-Pastor, E.; Andrade, F.; Sánchez-Pastor, J.M.; Elizalde, A.; Huerta, M.; Virgen-Ortiz, A.; Trujillo, X.; Rodríguez-Hernández, A. Cannabinoid receptor type 1 activation by arachidonylcyclopropylamide in rat aortic rings causes vasorelaxation involving calcium-activated potassium channel subunit alpha-1 and calcium channel, voltage-dependent, L type, alpha 1C subunit. Eur. J. Pharmacol. 2014, 729, 100-106. [CrossRef]

45. Kim, J.E.; Choi, B.K.; Choi, J.Y.; Ryu, T.; Roh, W.S.; Song, S.Y. Role of calcium channels responsible for phenylephrine-induced contraction in rat aorta 3 days after acute myocardial infarction. Korean J. Anesthesiol. 2014, 66, 143-152. [CrossRef] [PubMed]

46. Huang, C.C.; Aronstam, R.S.; Chen, D.R.; Huang, Y.W. Oxidative stress, calcium homeostasis, and altered gene expression in human lung epithelial cells exposed to ZnO nanoparticles. Toxicol. In Vitro 2010, 24, 45-55. [CrossRef] [PubMed]

47. Wu, J.; Zhang, Y.; Yin, Q.; Cui, G.; Shao, L. Endothelial Barrier Dysfunction Induced by Zinc Oxide Nanoparticles InVivo and InVitro and Their Mechanism of Crossing the Endothelial Barrier. J. Biomed. Nanotechnol. 2019, 15, 443-461. [CrossRef]

48. Farah, C.; Michel, L.; Balligand, J.L. Nitric oxide signalling in cardiovascular health and disease. Nat. Rev. Cardiol. 2018, 15, 292-316. [CrossRef] [PubMed]

49. Sarott, R.C.; Viray, A.E.G.; Pfaff, P.; Sadybekov, A.; Rajic, G.; Katritch, V.; Carreira, E.M.; Frank, J.A. Optical Control of Cannabinoid Receptor 2-Mediated Ca2+ Release Enabled by Synthesis of Photoswitchable Probes. J. Am. Chem. Soc. 2021, 143, 736-743. [CrossRef]

50. Aweimer, A.; Jettkant, B.; Monsé, C.; Hagemeyer, O.; van Kampen, V.; Kendzia, B.; Gering, V.; Marek, E.M.; Bünger, J.; Mügge, A.; et al. Heart rate variability and cardiac repolarization after exposure to zinc oxide nanoparticles in healthy adults. J. Occup. Med. Toxicol. 2020, 28, 15-24. [CrossRef] [PubMed]

51. Li, Y.; Li, F.; Zhang, L.; Zhang, C.; Peng, H.; Lan, F.; Peng, S.; Liu, C.; Guo, J. Zinc Oxide Nanoparticles Induce Mitochondrial Biogenesis Impairment and Cardiac Dysfunction in Human iPSC-Derived Cardiomyocytes. Int. J. Nanomed. 2020, 15, 2669-2683. [CrossRef] [PubMed] 
52. Weng, S.; Sprague, J.E.; Oh, J.; Riek, A.E.; Chin, K.; Garcia, M.; Bernal-Mizrachi, C. Vitamin D deficiency induces high blood pressure and accelerates atherosclerosis in mice. PLoS ONE 2013, 8, e54625. [CrossRef] [PubMed]

53. Lu, H.; Cassis, L.A.; Daugherty, A. Atherosclerosis and arterial blood pressure in mice. Curr. Drug Targets 2007, 8, 1181-1189. [CrossRef] [PubMed] 